\title{
Chapter 6 \\ Experimental Investigation on AE \\ Precursor Information of Rockburst
}

\subsection{Introduction}

Macro-fracture of rockmass is caused by nucleation, extension and propagation from micro-cracks among the meso-structures. So, it is important to obtain the evolution pattern from micro-facture to meso-scale. Rock fracture is accompanied with crystal dislocation, crystals slip, elastoplastic deformation, crack initiation, and propagation. Meanwhile, energy is released in the form of stress waves which can be monitored. Stress wave monitoring techniques, such as AE and micro-seismic (MS) monitoring, have been used for many decades to study the fracturing behavior of rock. As an important method of dynamic hazard monitoring, it can obtain the intensity and frequency of microseismic events activity and the location distribution of microseismic events, so we can estimate the potential dynamic hazard and obtain the precursory information to achieve the predicting hazards.

However, it is difficult to achieve the field practice from the rock experiment. Meanwhile, the lab test is an effective method to research the rock failure. Therefore, it's the primary task to analyze the changing characteristics and the precursory information pattern of rockburst.

In recent decades, many scholars obtained some relevant research in precursory information characteristics of rockburst. Under uniaxial compression test, the appeared relatively quiet period of $\mathrm{AE}$ was found before the rock failure, and this phenomenon was used as precursory information of rockburst (Wang 2014). Carpinteri et al. (2007) found that the rate of AE energy was accelerating before the sample failure. Lacidogna et al. (2011) found that AE signal was consistent with damage and evolution process of brittle rock, and taken the action that the stress was deeply down as failure precursor. Wang et al. (2015a, b) found relative quiet period before the rock failure, the predicting point of rockburst was proposed and some correlative theories were obtained in field practice. Meng et al. (2016) analyzed the energy evolution feature of red sandstone deformation under the different cycle loading rates. Furthermore, the implied conversion pattern between energy 
with dissipation, Carpinteri and Lacidogna (2006) analyzed evolving relation between AE energy and dissipation energy under the concrete beam loading using the three point bending test.

In a word, many scholars conducted lots of AE experiments; most of their work was focused on the relationship between AE parameters with rock fracture and failure. However, in this chapter, the precursor of rock failure was utilized to predict rockburst using the distribution feature and evolution pattern of AE/MS in the deep mining.

\subsection{Spatio-temporal Evolution Pattern of Rock Failure}

Under the external loading, the virgin rock cracks were initiated, propagated, and linked. At the same time, AE events were released in the form of elastic stress waves. Therefore, with the spatial-temporal distribution characteristics of $\mathrm{AE}$ source 3D-location, the characteristics of rock cracks initiating, propagating and linking was analyzed, AE evolution regular and the precursor feature of limestone failure were revealed finally.

\subsubsection{AE Experiment}

In this experiment, 10 limestone specimens were divided into two groups. During the testing, the axial equivalent displacement loading method was used to load the specimens, and AE monitoring system was synchronously operated. The loading speed was controlled at $0.5 \mathrm{~mm} / \mathrm{min}$. In the AE monitoring testing, data collection was performed six channels, and the sampling frequency was set at $1 \mathrm{MHz}$. The threshold voltage value was set at $100 \mathrm{mv}$ and the threshold amplitude value was set at $45 \mathrm{~dB}$. AE signals would be filtered for removing noise signals, and a high signal/noise ratio could be achieved. During the test, six nano30 sensors were used to monitor AE signals and the pre-amplifier gain was set at $40 \mathrm{~dB}$. The sensors were fixed on rock surface by adhesive band and petroleum jelly. In order to reduce the influence of the end effect, there should be $20 \mathrm{~mm}$ distances between the end of samples and the sensors. The layout of AE sensors were illustrated in Fig. 6.1.

\subsubsection{Principle of AE Event Location}

In order to locate the micro-cracks inside rock sample by $\mathrm{AE}$ monitoring, the sensors were arranged in a geometric pattern to form the sensor array on the surface of rock sample. The location of AE source was then determined based on AE signal parameters and location methods. 
Fig. 6.1 The arrangement of AE sensors (Unit mm)

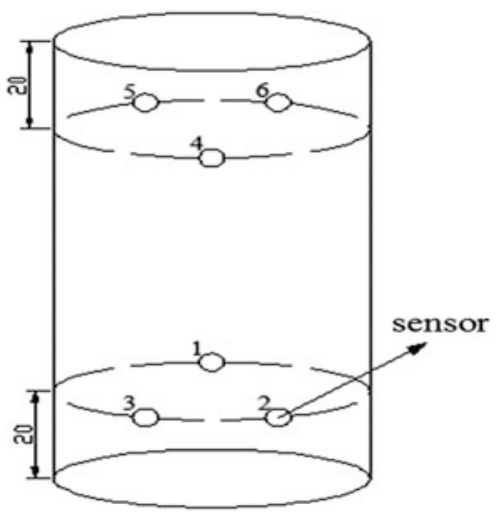

For the sudden type of AE signals, time difference location method and regional location method were mainly used to achieve the goal. Combined with the spatial location of sensor, $\mathrm{P}$ wave velocity and other related parameters, the former method was usually use as the measurement of parameters, such as the time difference among AE channel signals reaching the sensors to determine the location of $\mathrm{AE}$ source by the simplex algorithm or the Geiger algorithm. This location method was widely used in small rock samples and large components because of its higher accuracy, though the calculation was more complex than the latter one. Due to the simpler location operation and higher processing speed, the regional location method was generally applicable to situations where the location accuracy was low and the time difference could not be located.

The simple location algorithm and Geiger location algorithm (Miller et al. 1999) were two commonly used algorithms of AE location. The principle of these two algorithms was to invert the location of $\mathrm{AE}$ source by picking up the P-wave arrival time difference through different position sensors. Geiger algorithm was one of Gauss-Newton minimum fitting function applications, which was suitable for AE/ MS and earthquake events in small areas. In this chapter, Geiger algorithm was used to locate the AE source based on the time difference between the arrivals of $\mathrm{P}$ wave. In order to determine the real AE source coordinates, this algorithm was done by iterating over a hypothetical AE source. In each iteration process, a correction vector $\Delta \theta$ was calculated by least squares method, and added it to the previous iteration result to obtain a new $\mathrm{AE}$ source location coordinate, then put the new coordinate parameters into the time-distance equation (6.1) to judge whether the new coordinate satisfies the equation. If the requirement was met, the new coordinate was the location of AE source; otherwise, it was need to continue iterating until the time distance equation was satisfied. In the AE location test, sensors were arranged in accordance with Fig. 9.3, and the location of $\mathrm{AE}$ events could be determined by measuring the relative time difference between each sensor picking up the $\mathrm{P}$ wave. 
The time-distance discriminant equation for the iteration results is as follows:

$$
\left(x_{i}-x\right)^{2}+\left(y_{i}-y\right)^{2}+\left(z_{i}-z\right)^{2}=\left[v_{p}\left(t_{i}-t\right)\right]^{2}
$$

where $x, y, z$ are the initial assumed AE source coordinates; $t$ is the time at which the initial $\mathrm{AE}$ event occurs; $x_{i}, y_{i}, z_{i}$ are the spatial coordinates of $i$ th sensor, respectively; $v_{p}$ is the velocity of $\mathrm{P}$ wave; $t_{i}$ is the time that the $i$ th sensor picks up the $\mathrm{P}$ wave.

The time at which the $\mathrm{P}$ wave propagates to the $i$ th sensor is $t_{0, i}$, The first-order Taylor expansion of $\mathrm{P}$ wave arrival time can be calculated using the initial assumed AE source coordinates:

$$
t_{0, i}=t_{c, i}+\frac{\partial t_{i}}{\partial x} \Delta x+\frac{\partial t_{i}}{\partial y} \Delta y+\frac{\partial t_{i}}{\partial z} \Delta z+\frac{\partial t_{i}}{\partial t} \Delta t
$$

where,

$$
\begin{gathered}
\frac{\partial t_{i}}{\partial x}=\frac{x_{i}-x}{v_{p} R}, \quad \frac{\partial t_{i}}{\partial y}=\frac{y_{i}-y}{v_{p} R}, \quad \frac{\partial t_{i}}{\partial z}=\frac{z_{i}-z}{v_{p} R}, \quad \frac{\partial t_{i}}{\partial t}=1, \\
R=\sqrt{\left(x_{i}-x\right)^{2}+\left(y_{i}-y\right)^{2}+\left(z_{i}-z\right)^{2}}
\end{gathered}
$$

where $t_{c, i}$ is the time that the $\mathrm{P}$ wave spread from the assumed AE point coordinates to the $i$ th sensor. There were six sensors in this experiment for three-dimensional location. Therefore, six equations were listed in the form of a matrix as follow:

$$
\left[\begin{array}{cccc}
\frac{\partial t_{1}}{\partial x} & \frac{\partial t_{1}}{\partial y} & \frac{\partial t_{1}}{\partial z} & 1 \\
\frac{\partial t_{2}}{\partial x} & \frac{\partial t_{2}}{\partial y} & \frac{\partial t_{2}}{\partial z} & 1 \\
\vdots & \vdots & \vdots & \vdots \\
\frac{\partial t_{6}}{\partial x} & \frac{\partial t_{6}}{\partial y} & \frac{\partial t_{6}}{\partial z} & 1
\end{array}\right]\left(\begin{array}{c}
\Delta x \\
\Delta y \\
\Delta z \\
\Delta t
\end{array}\right)=\left(\begin{array}{c}
t_{0,1}-t_{c, 1} \\
t_{0,2}-t_{c, 2} \\
\vdots \\
t_{0,6}-t_{c, 6}
\end{array}\right)
$$

The modified vector $\Delta \theta$ in Eq. (6.3) was solved by Gauss elimination method, which was $\Delta \theta=[\Delta x, \Delta y, \Delta z, \Delta t]$. After the modified vector $\Delta \theta$ was calculated for each possible $\mathrm{AE}$ source coordinate matrix, the iteration was continued with $(\theta+\Delta \theta)$ as the new coordinates until the Eq. (6.1) was satisfied. At this time, the satisfied coordinates could be used as the real location. 


\subsubsection{Spatio-temporal Distribution Characteristics of Rock Failure}

As the primary micro-cracks closed, expanded and linked, each sample generates lots of $\mathrm{AE}$ events in the entire loading process. The collecting system could be manipulated the $\mathrm{AE}$ date and obtained the visualized location images. Take only X2 sample date for example, as shown in Figs. 6.2 and 6.3.

As shown in Fig. 6.2, when the stress was at low level $\left(<0.2 \sigma_{c}\right)$, AE activity was active and gathered round middle part and top part of sample. This phenomenon could be explained as follows: in one hand, the original developmental cracks of samples were gradually closed under compression loading; on the other hand, a small quantity of $\mathrm{AE}$ events were occurred because of friction between samples and the pressure plate of machine. In the elastic deformation and stable growth crack stage $\left(0.4-0.6 \sigma_{c}\right)$, AE counts increased steadily and accompanied with the development of microfracture. AE events dispersed gradually from the middle part to around part. When stress increased at the $0.8 \sigma_{c}$, AE events increased quickly and gathered round the main fracture, which presented obvious zonal distribution. The sample surface began showing the macrocrack, and AE event increased. In the post-failure stage, AE activities did not stop, but stress dipped quickly.

As the spatial distribution of AE events change with the loading time, we have analyzed the feature of spatio-temporal evolution in the different loading stage.

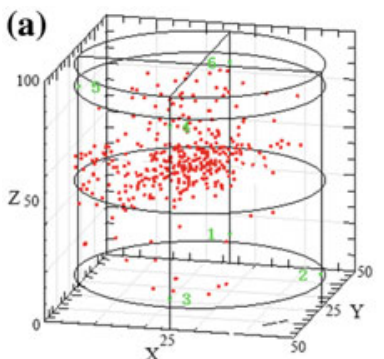

(d)

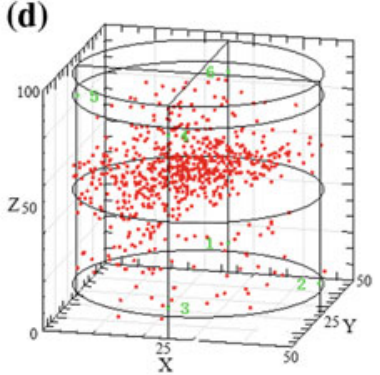

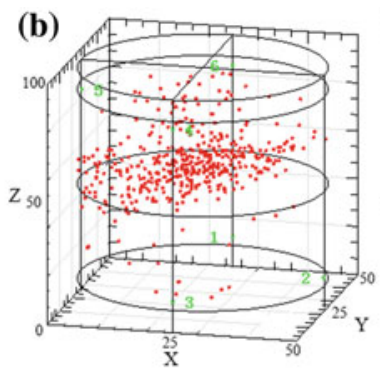

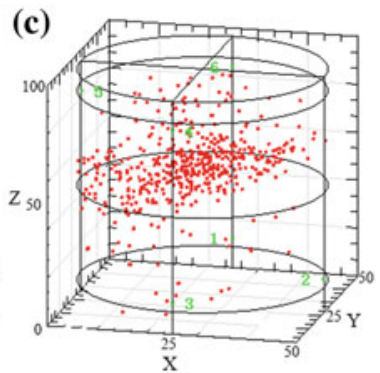

(e)

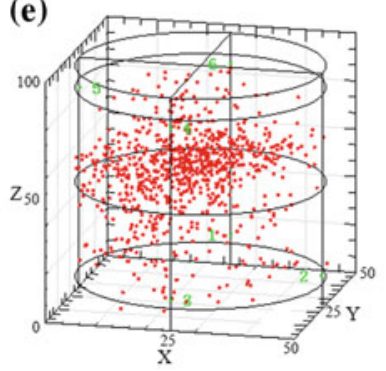

Fig. 6.2 AE distribution of $\mathrm{X} 2$ sample during the different loading period 

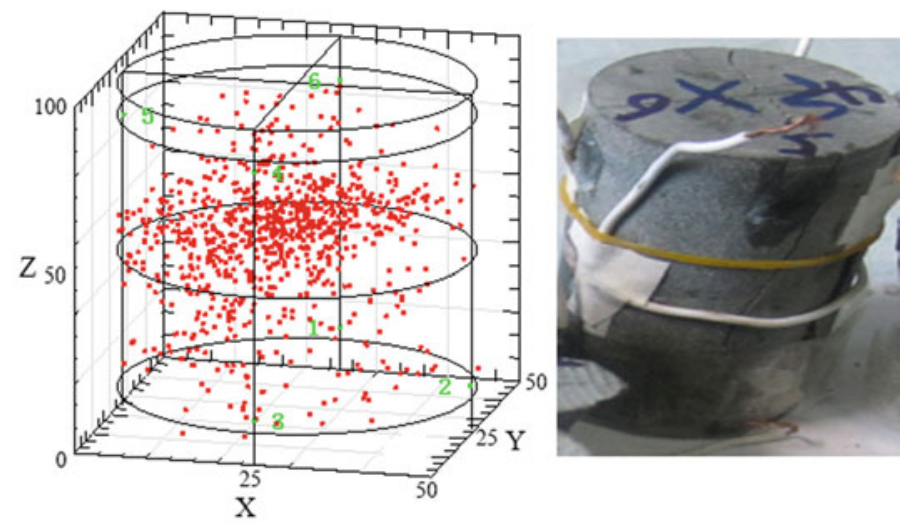

Fig. 6.3 Comparison of AE localization and actual rupture propagation

Though the distribution was very heterogeneous, we still found two main phenomenons after summarizing all sample results, as shown in Figs. 6.2 and 6.3:

(1) Intensive phenomenon: It was easy to be found that AE events occurred mainly in the middle part of X2 sample. However, when the stress increased to the 40, 60 and $80 \%$ of peak stress, AE events were always around the main plane of fracture, and only few events was in others parts. Therefore, it was an effective way to predict roughly the final position and attitude of main fracture plane using the spatial distribution of AE event.

(2) Zonation: AE events internal sample presented the obvious zonate shape, and the location of shape was basically consistent with the final macro-fracture. The main fracturepart from the zonation was shown.

\subsection{Characteristics of Relatively Quiet Period for Rock Failure}

\subsubsection{Deformation and Failure Characteristics of Loaded Rock}

Stress-strain curves of limestone samples were shown in Fig. 6.4, the deformation trend of a specimens were similar during the entire loading process. There are four basic stages of variation trend, including the original crack compaction, the stable crack growth, the unstable crack propagation and the rock failure stage (Wang et al. $2015 a, b)$. In the chapter, only one sample was choosed to analyze and discuss the mechanical properties and AE characteristics of the loaded rock. As shown in Fig. 6.6, the sample No. 3 was appeared the original crack compaction stage after 


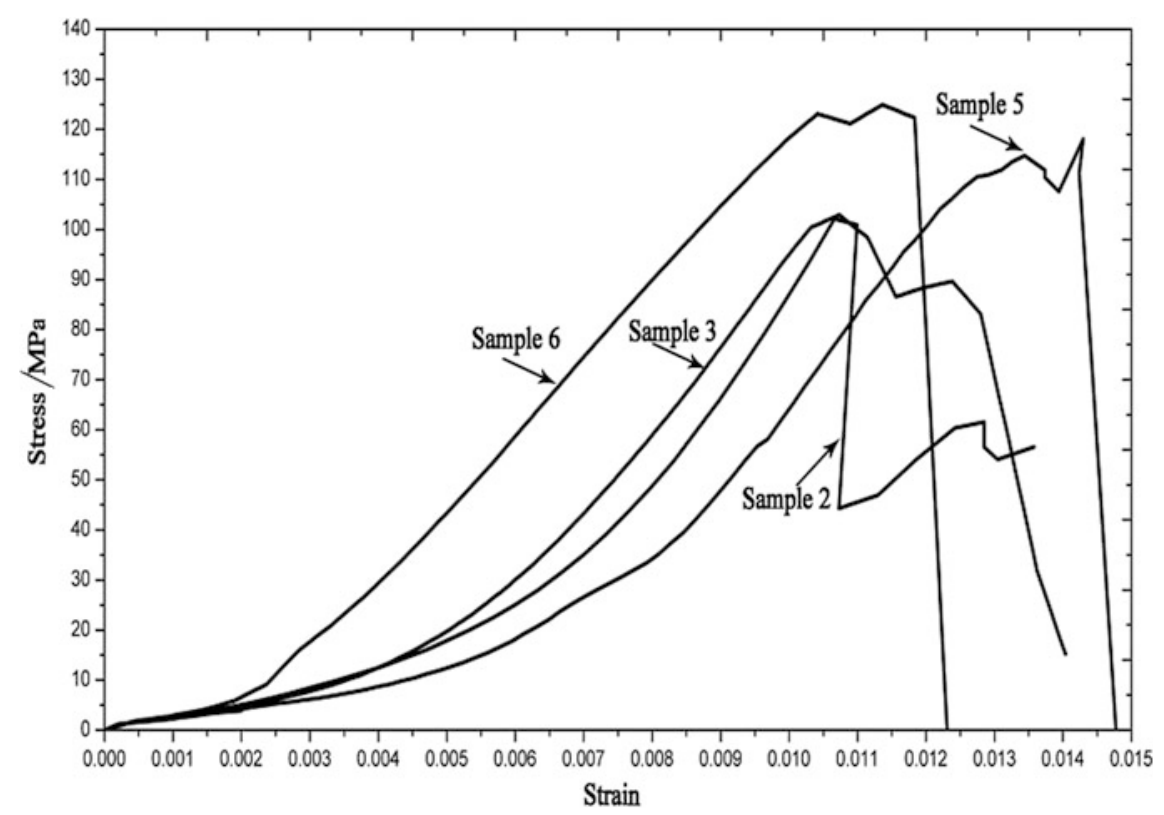

Fig. 6.4 Stress-strain curves of samples. With kind permission from "AMER SOC TESTING MATERIALS", Wang et al. (2015b), 1296-1307 Fig. 6, all rights reserved

the beginning of uniaxial compression. With the stress increasing, the sample came into elastic deformation and the curve remained linear variation because of stable crack growth, it spended for a long time. Cracks initiated, extended and developed into the unstable propagation. In the plastic deformation stage, curve started to change non-linearly and rock volume also increased slightly. It was thought that many micro-fractures propagated and jointed one another which caused the volume increase of mesostructures. When the microcracks jointed and formed into macroscopic cracks, rock relative stability was destroyed, and stress reached the peak 102.89 MPa (Wang et al. 2015a, b). Stress didn't dipped sharply after the peak, and rock still had certain supporting ability. Therefore, there was secondary stress drop in the post-failure stage. Due to heterogeneity of rock, there was different destruction style, such as oblique shear failure and tensile failure. In the same way, the different mechanical properties of samples was because the size and the heterogeneity of rockmass. The analyzation of rock mechanical properties was important to understand the AE phenomenon (Wang et al. 2015a, b). 


\subsubsection{Relationship Between the Constitutive Characteristics and the Accumulative AE Counts}

We could clearly find the relationships of sample No. 3 between stress-strain curve and the accumulative AE counts in Fig. 6.5. AE activity was constantly changed during the whole uniaxial loading (Wang et al. 2015a, b). However, there were still several changing characteristics in the accumulative AE counts. Before stress reached $20 \%$ of the peak stress, the original cracks were gradually closed and the friction occurred between samples and the pressure plate which generated a quantity of AE events occurred, the slope of this stage was larger than the slope of the elastic stage in the accumulative count curve. In the elastic deformation stage, cracks were in stable growth, and AE activity appeared obviously changing trend at the $30 \%$ of the peak stress, which we could regard as the Kaiser Effect point. From 30 to $60 \%$ of the peak stress, AE accumulative counts were linearly increased, which meanted AE activity stably developing. From Fig. 6.5, it was easy to discover that AE activity was unstable by comparison, which laterally reflected the heterogeneity of rock properties. When stress reached $60 \%$ of the peak stress, rock came into the plastic deformation stage and $\mathrm{AE}$ activities were enhanced. When stress was approximately at $75 \%$ of the peak stress, there were almost no AE activity and this phenomenon lasted $5 \mathrm{~s}$. In other words, the sample deformation was in a relatively

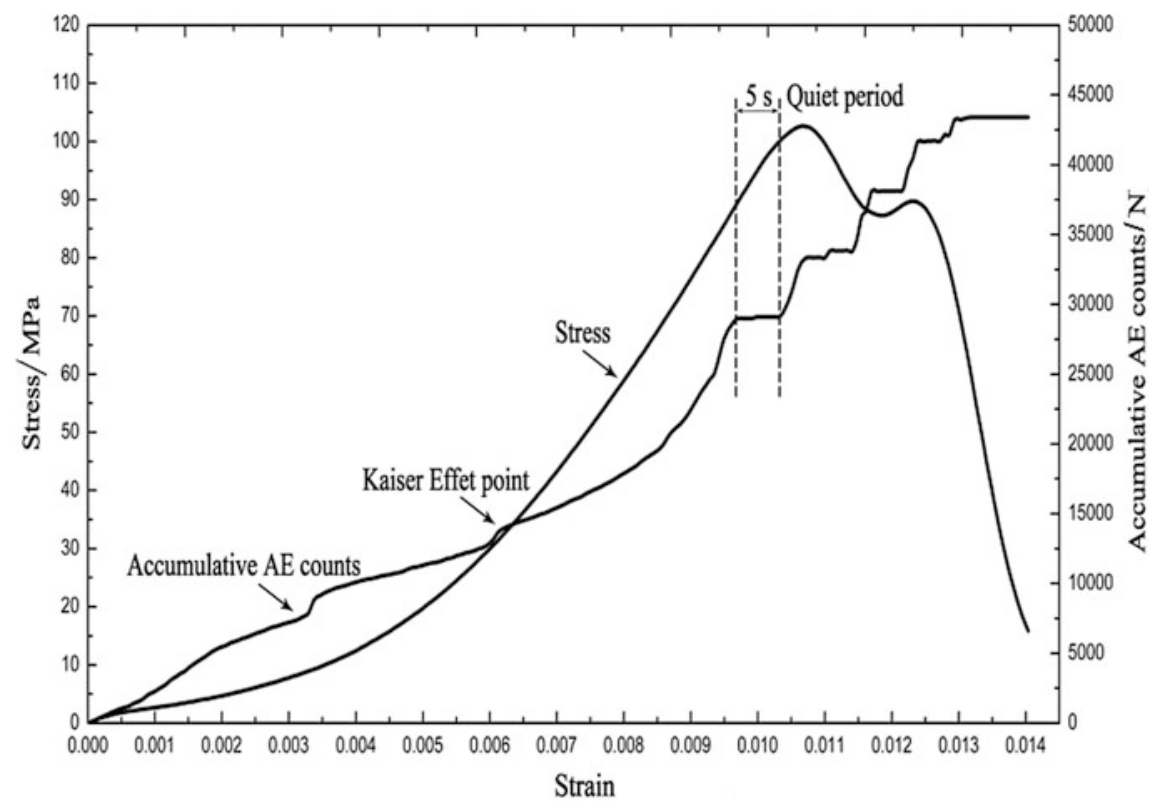

Fig. 6.5 Relationship between stress-strain curves and accumulative AE counts for limestone sample. With kind permission from "AMER SOC TESTING MATERIALS", Wang et al. (2015b), 1296-1307 Fig. 7, all rights reserved 
quiet period as marked in Fig. 6.5. Then AE activity generated actively. When stress passed through the yield-point to peak stress, AE activities were rapidly enhanced, and the parameters of AE events were also increased, such as the amplitude, energy, frequency, duration, et al, which implied the magnitude of AE event stronger, and the size of fracture bigger. Therefore, in author's opinion, we could use the relatively quiet period as the precursor of rock failure to provide a predicting signal for rockmass instability. Similarly, we could use this opinion to analyze the micro-seismic events of seismicity to evaluate the rockmass stability in mining engineering (Wang et al. 2015a, b). After the peak stress, rock damage was in the post-failure, but AE activities did not stop, and intermittent emission constantly appeared. With stress declining, AE count increased periodically.

\subsubsection{Relationship Between AE Rate and Constitutive Characteristics}

Due to the samples inhomogeneous, mechanical and AE characteristics are nonlinear under uniaxial compression. Meanwhile, AE rate represents the intensity of AE activity and the developing speed of rock microcrack. Therefore, AE parameters of time domain can clearly reflect the real-time damage evolution, such as AE rate, $\mathrm{AE}$ energy rate and $\mathrm{AE}$ amplitude. $\mathrm{AE}$ duration and $\mathrm{AE}$ frequency reflect the properties of single $\mathrm{AE}$ event. In order to legibly understand the characteristics of $\mathrm{AE}$ and find the feature of $\mathrm{AE}$ relatively quiet period, we need to analyze $\mathrm{AE}$ parameters respectively.

$\mathrm{AE}$ rate is a sensitive parameter about real time, which can reflect the frequency of $\mathrm{AE}$ activities and evaluate the damage status. The relationships between the constitutive characteristics and AE rate about the sample NO. 3 are shown in Fig. 6.6.

From the above, it was easy to discover that $\mathrm{AE}$ activity was always active during the whole uniaxial compression. As shown in Fig. 6.6, AE accumulative count appeared a small increase at $15 \%$ of the peak stress. We also found AE rate sharply increased to 800 at $25 \mathrm{~s}$ which was caused by inhomogeneous development of microcrack in the sample. In the initial deformation stage, AE rate increased firstly which implied the initial microcavities closed gradually. After $10 \mathrm{~s}$, the rate became dipping trend and appeared a sharp increase around the time $25 \mathrm{~s}$. Then AE activity maintained steady change in the elastic rock deformation, and the rate also appeared an obvious increase at the Kaiser Effect point. In the plastic deformation damage, the rate increased gradually and stress appeared the linear increase. In this stage, cracks propagation was unstable, and micro-cracks merged progressively. Before $70 \mathrm{~s}$, the rate appeared a sharp increase, but stress curve didn't appear any dip trend. However, AE rate decreased sharply afterwards and there was a relatively quiet period appeared and lasted $5 \mathrm{~s}$ before the stress reached the peak stress. The loaded sample quickly passed through the quiet period before the arrival of the peak 


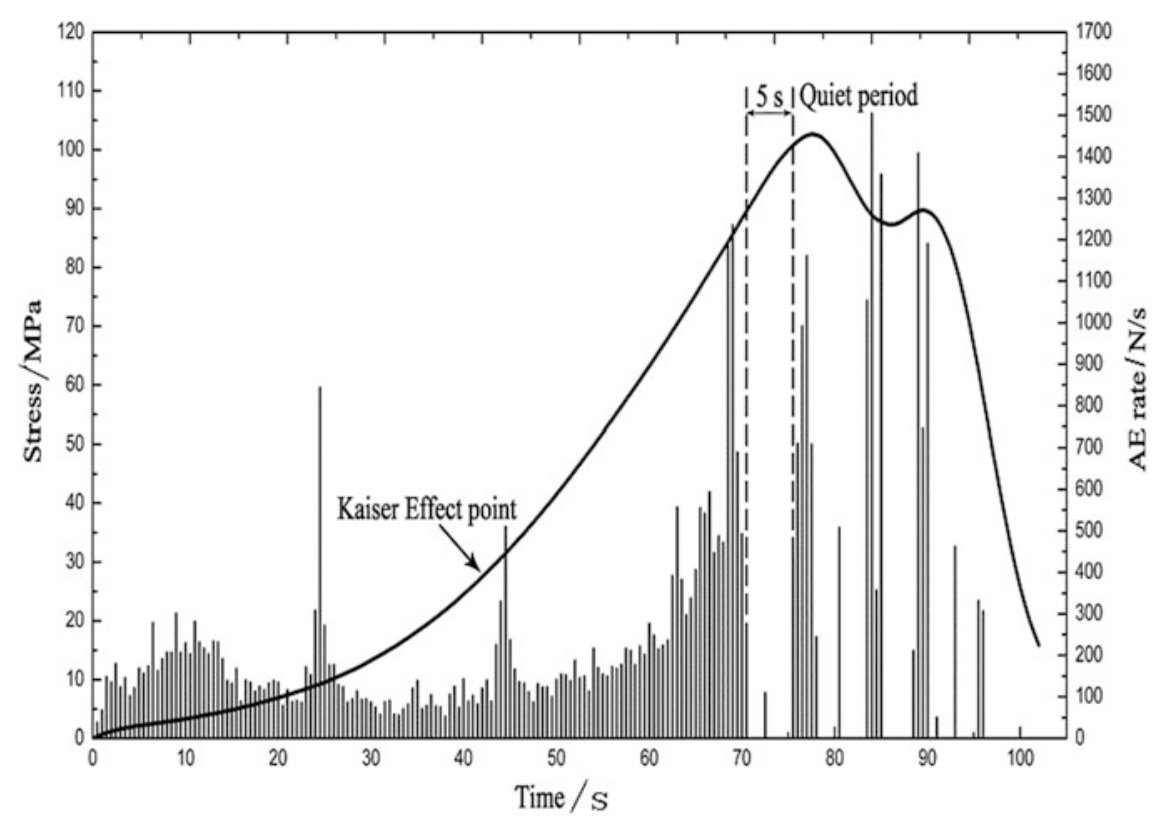

Fig. 6.6 Relationship between stress-time curves and AE rate for limestone sample. With kind permission from "AMER SOC TESTING MATERIALS", Wang et al. (2015b), 1296-1307 Fig. 8, all rights reserved

stress. AE rate increased rapidly when stress reached the peak. In the post-failure damage, $\mathrm{AE}$ rate became intermittent and several periods appeared with the process of stress decline. From the change trend of AE activity in the failure stage, we could easily find how strong the intensity of rock damage (Wang et al. 2015a, b).

\subsubsection{Evolution Characteristics of AE Amplitude in the Time Domain}

Figure 6.7 was a scatter diagram in which each scatter point represents a single AE event. AE amplitude was the maximum amplitude value of each $\mathrm{AE}$ wave which could be gained by Fourier Transform, which reflected the magnitude and intensity of $\mathrm{AE}$ activity. In view of the effectivity of $\mathrm{AE}$ extraction and the environment noise, we set the threshold at $45 \mathrm{~dB}$. Therefore, the minimum amplitude of $\mathrm{AE}$ signals was $45 \mathrm{~dB}$. As shown in Fig. 6.7, most amplitude of AE signals was below $60 \mathrm{~dB}$, and few of $\mathrm{AE}$ signals were beyond $80 \mathrm{~dB}$. As the amplitude reflected $\mathrm{AE}$ event energy directly, majority of AE events were had low-energy. On the contrary, only $0.7 \%$ of the total events were high energy. In other words, local slight fractures generated in the samples during the entire loading process. In the initial loading 


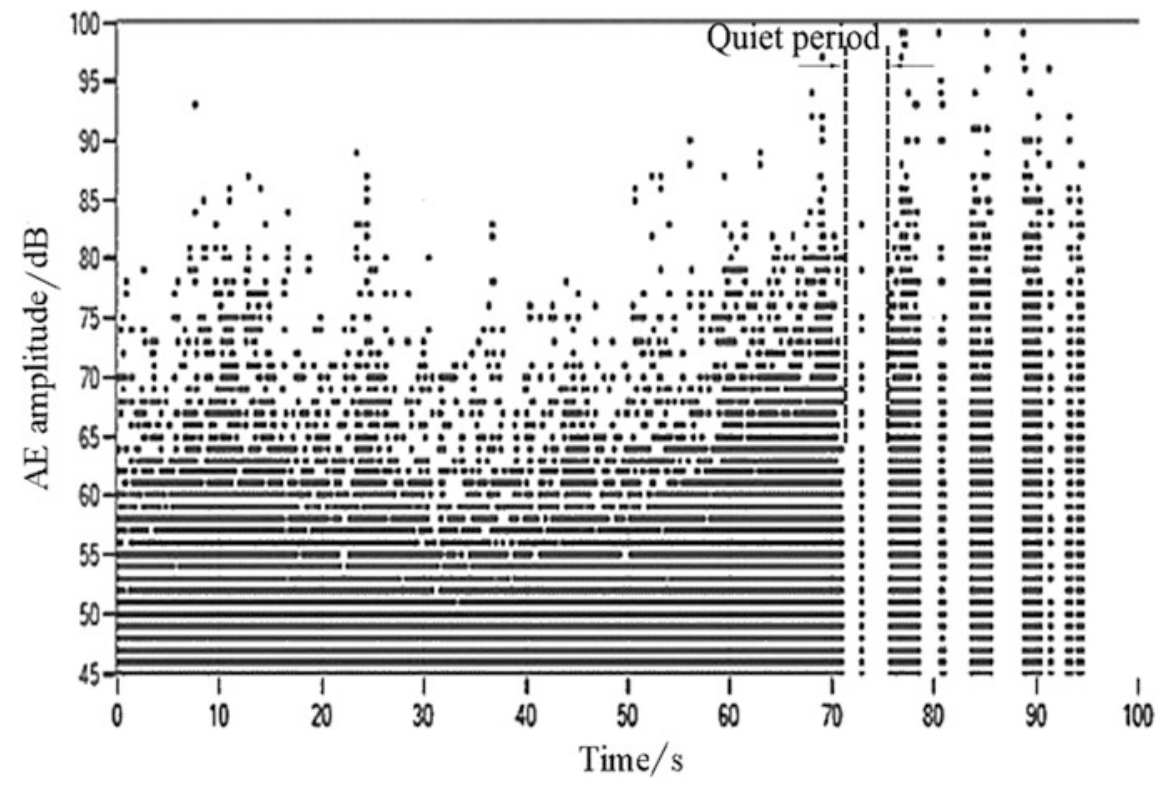

Fig. 6.7 Relationship between $\mathrm{AE}$ amplitude and time for limestone sample. With kind permission from "AMER SOC TESTING MATERIALS", Wang et al. (2015b), 1296-1307 Fig. 10, all rights reserved

stage, most of low-energy AE events were generated, and some of amplitudes began distributing beyond $80 \mathrm{~dB}$, which represented the completion of carities closing and the beginning of microcracks propagation. In the elastic deformation, the AE amplitudes were steady distributed in the time domain. But in the plastic deformation stage, the amplitudes presented the ascent distribution. Then in the unstable crack propagation stage, lots of high-amplitude AE signals appeared rapidly. When stress reached $75 \%$ of the peak stress, a relatively quiet period appeared as shown in Fig. 6.7. After the peak stress, rock strain began softening, and many high-amplitude and high-energy AE events were generated in the same time, which reflected the high energy was releasing with rock failure instability (Wang et al. 2015a, b).

\subsubsection{Analyzation of Precursory Characteristics of Rock Failure}

During the testing, a relatively quiet period of $\mathrm{AE}$ generation was found before rock failure during the test. To some extent, AE activities implied stress state of micro-fracture and reflected the damage evolution in the rock. But there must be some factors which caused the AE intermittent existed in the whole compress process. 
On the one hand, with uniaxial compressive stress increasing, strain energy of rock system transformed as deformation energy and dissipated energy. In the different deformation stages, energy percent of deformation and dissipation was relatively changing, which could be due to rock inhomogeneity, deformation energy could be also divided into volume energy and fracture energy, as the dissipated energy could be divided into the thermal energy, AE energy and radiant energy. The dissipated energy could be regarded as energy release with system energy import. Therefore, there was a balanced time domain in the process of energy import and energy release, which caused the propagation of micro-cracks, and energy release reach dynamic and temporary balance before the peak stress. This is one of reasons we can see the relatively quiet period in the loaded time domain.

On the other hand, high-damage intensity caused the sharp attenuation of $\mathrm{AE}$ propagation before the peak stress. There were many microstructural cracks existed in sample, which caused inhomogeneity of rock properties. Therefore, the propagation of $\mathrm{AE}$ waves was badly effected and the quiet period appeared. With stress increased, the state of balance was broken, and macro-fracture was formed causing the stress dip. The relatively quiet period might be mainly caused by inhomogeneity of samples (Wang et al. 2015a, b).

Therefore, we can use the AE quiet period as precursory information for prediction of rock failure and the practical engineering applications.

\subsection{Variation Regulation of AE Energy Parameters for Rock Failure}

\subsubsection{Experimental Setup and Procedure}

In the experiment, 10 granite specimens were tested, approximately $50 \mathrm{~mm}$ in diameter and $100 \mathrm{~mm}$ in height. The loading machine and $\mathrm{AE}$ testing system were operated at the same time to obtain the mechanical behaviors and AE dates of specimens under uniaxial compression. The loading speed was $0.005 \mathrm{~mm} \times \mathrm{s}^{-1}$. In addition, AE sampling frequency was set at $1 \mathrm{MHz}$. Six AE sensors were pasted on the surface of sample to detect $\mathrm{AE}$ waves. The pre-amplifiers were set at $40 \mathrm{~dB}$. Moreover, eliminating the influence of background noise, the threshold value of PCI-II acquisition system was set at $45 \mathrm{~dB}$.

\subsubsection{Energy Parameters Variations in Each Channel}

As six sensors were installed on the sample surface, it was meant that there were six channels could detect the same AE waves. Due to the inhomogeneity of rock properties, the attenuation of $\mathrm{AE}$ signal might be different in local positions. 
Fig. 6.8 AE energy parameter variations for each channel. From Wang et al. (2015a, b)

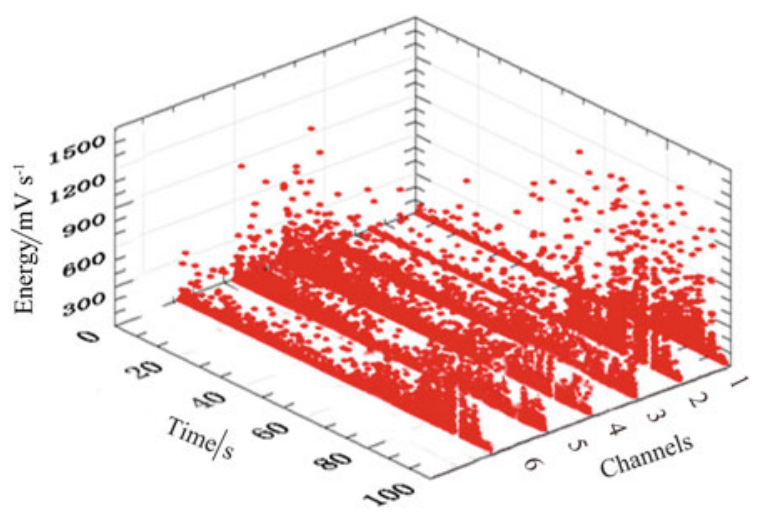

Therefore, one AE signal might be detected by the different position sensors, and some of sensors might not receive the signal, which caused AE energy parameter variations were different for each channel. Variation trend of AE energy was shown in Fig. 6.8, energy of 6 channels almost had the same variation trend. In the initial loading stage, AE energy increased firstly and then decreased subsequently. Energy of channel 1 and channel 2 was relatively insensitive, because the attenuation of AE energy was seriously when wave reached at the sensors. During the medium stage, AE energy kept plain evolution. After $70 \mathrm{~s}$, AE energy increased sharply and reached at the peak, which lasted in the almost the entire failure process. With the destruction of rock supporting stability, AE energy also sharply dipped. The reasons for this phenomenon could be explained as follow. The original inner cavities were compacted with lots of energy releasing. While in the elastic stage, rock deformation and cracks propagation were generally stable. Thus, AE energy release was also stable. However, as rock in the plastic stage, micro-fractures were in unstable expansion. Then, microcracks jointed macrocrack which led to rock failure while high energy fiercely released (Wang et al. 2015a, b).

\subsubsection{Relationship of Energy and Stress-Strain Curve on Time Domain}

As shown in Fig. 6.9, there was a fine relation between AE energy release and constitutive characteristics of loaded rock. It was obvious to find that most of $\mathrm{AE}$ signal energy was $300 \mathrm{MV} / \mathrm{s}$, and high energy event appeared in high stress stage, which directly reflected the stability of damage evolution. AE energy had different stages of relevant changing characteristics, describing as follow: the original crack compaction stage, the elastic deformation stage, the plastic deformation stage and the failure stage. During the first stage and the second stage, rock got the compression, but rock kept strong elastic property, so stress can be linearly developing. In this stage, a lot of $\mathrm{AE}$ waves had been generated with the cavities compaction 
and cracks initiation. In the third stage, rock sample was in plastic deformation and cracks developing were relatively stable. Before the yield stress, there was relatively stable AE energy release which reflected the balance of energy transformation. After $65 \mathrm{~s}$, stress curve bagan changing in the unstable slope, directly reflecting the strain unstability. Meanwhile, many high energy signals were generated and implied the intense cracks expansion (Wang et al. 2015a, b). Therefore, variation characteristics could be applied to replace the field stress monitoring as the evaluation factors of rockmass stability. As AE signal energy increased abruptly, it could be thought as the precursor for rock rupture.

\subsubsection{Analysis of Damage Features}

As shown in Fig. 6.9, high AE energy began appearing after $65 \mathrm{~s}$, which meant high-intensity damage in the sample. Therefore, it was very important to analyze the energy evaluating characteristics of this period. In this chapter, we selected the summation energy, average energy and maximum energy to analyze as shown in Figs. 6.10, 6.11, and 6.12. Three kinds of energy are defined as follow:

Summation of energy was the cumulative value of AE energy detected in all channels at the same time; the average of energy was the value as the total energy divided by the number of channels at a certain time; the maximum of energy was the maximum energy among each channel detected at a certain time. As the above, there should be pointed out that a channel could detect multiple energy signals in the same time, but each channel could not detect one event energy at the same time, which caused three values different at the same time point (Wang et al. 2015a, b).

As shown in Figs. 6.10, 6.11, and 6.12, three initial indexes were presented the same variation trend from 69 to $99 \mathrm{~s}$, but the values jumped in the time domain. So we had fitted the initial curve plotted in Figs. 6.10, 6.11, and 6.12. From the fitted

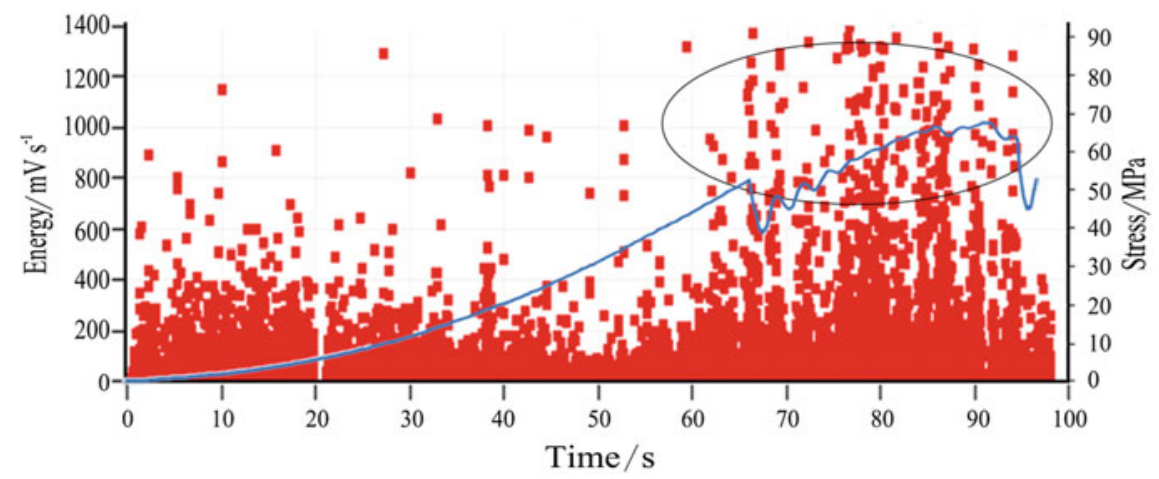

Fig. 6.9 Relationship between AE and stress with time. From Wang et al. (2015a, b) 


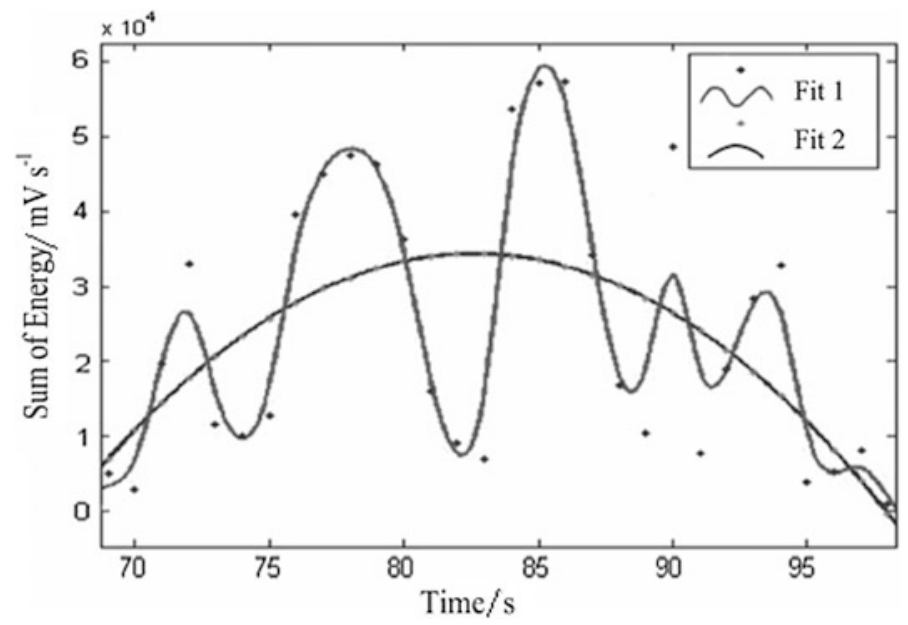

Fig. 6.10 Fitted curves of energy summation. From Wang et al. (2015a, b)

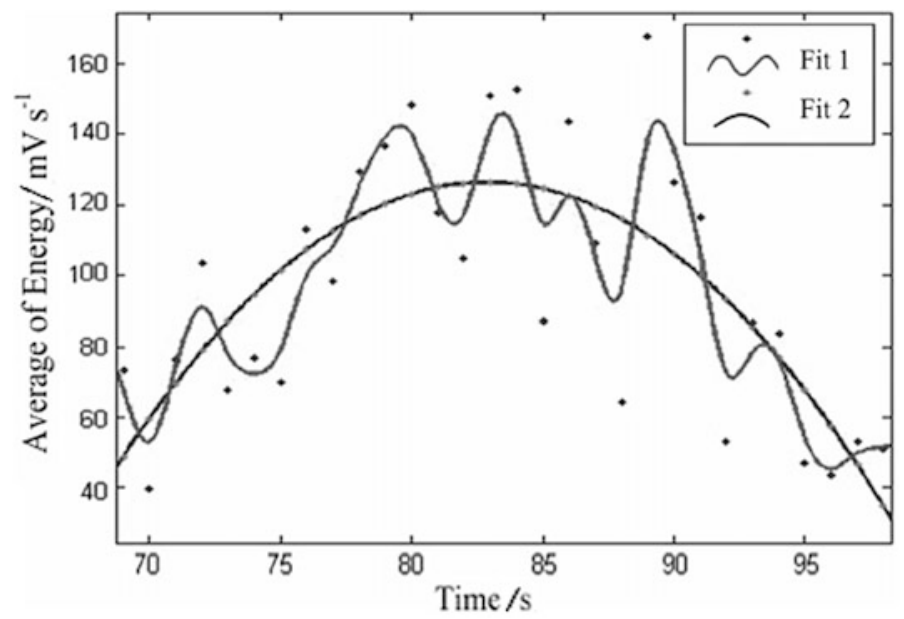

Fig. 6.11 Fitted curves of average energy. From Wang et al. (2015a, b)

curves, we could find that the energy values reached the maximum before $90 \mathrm{~s}$, indicating the maximum release of $\mathrm{AE}$ energy was before rock failure. Therefore, we estimated rock stable status by observing the variation of three indexes simultaneously. Compared with single energy index, we could more exactly judge rock energy release. Corresponding the fitted equations $f(\mathrm{t})$, summation of energy was obtained based on the experimental data as presented in Eq. (6.4). From derivation, the time of extreme values in the parabolic curves are $t_{1}, t_{2}$ and $t_{3}$, which could be used as the critical times (Wang et al. 2015a, b). 


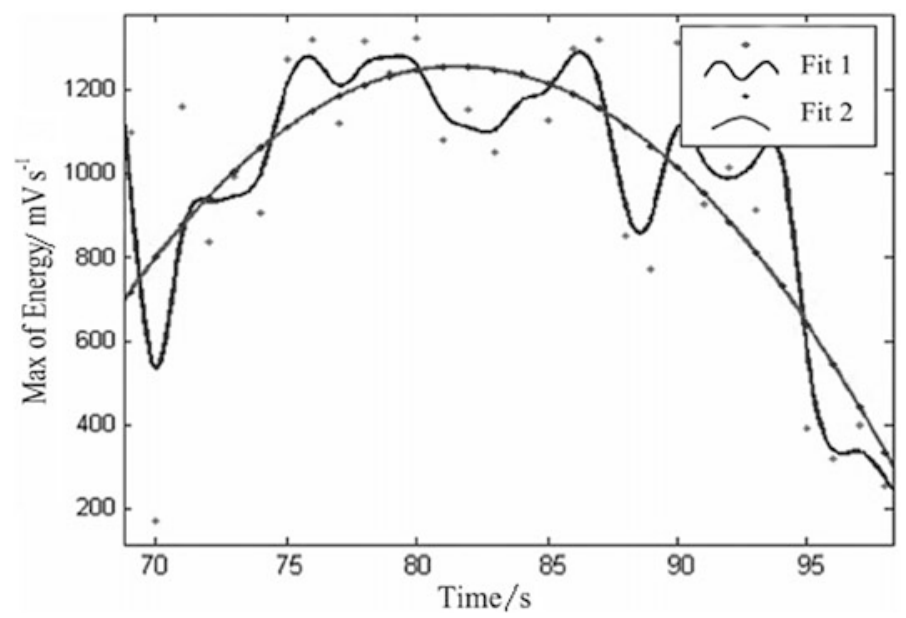

Fig. 6.12 Fitted curves of maximum energy. From Wang et al. (2015a, b)

The fitted curve of energy summation could be described as follow:

$$
f(t)=-147.2 t^{2}+24,330 t-971,000
$$

The time of the maximum value in energy summation curve could be obtained by the derivative of Eq. (6.5):

$$
f^{\prime}(t)=-294.4 t+24,330
$$

where $f^{\prime}(t)=0$, so $t_{1}=82.64$ s.

Based on the calculations above, the time of average energy, and the maximum energy could be obtained as $t_{2}=82.89 \mathrm{~s}$ and $t_{3}=81.57 \mathrm{~s}$. Calculated the average of $t_{1}, t_{2}$ and $t_{3}$ was $82.37 \mathrm{~s}$. It was obvious to find that the times of three indexs almost reached at the same time. Meanwhile, it was thought that the time of most intense $\mathrm{AE}$ energy release occurred around $82.37 \mathrm{~s}$ and regarded the point of time as a critical feature to predict rock failure (Wang et al. 2015a, b).

\subsubsection{Energy Release Rate of Rock Damage}

As shown in Fig. 6.9, as lots of scattered AE signals released, AE energy was always in dynamic evolution during the entire loaded process. Thus, it was hard to exactly describe the real energy release and the actual damage level. Then the concept of energy release rate was proposed, which referred to AE energy released per unit time, and eliminated the instability of AE release. Thereby, it was significative to further study the mechanism of energy release rate and analyze its reasonability. 
Being the numerical signal, AE energy is a quantitative description of continuous $\mathrm{AE}$ signals. From electronics theory, $\mathrm{AE}$ energy release rate is proportional to mean square voltage of $\mathrm{AE}$ signals, which means that the voltage can replace $\mathrm{AE}$ energy to describe the damage variation. Mean square voltage to calculating AE energy can be formulated as follows:

$$
E=\int_{t_{1}}^{t_{2}} V_{m s} d t
$$

Furthermore, the energy release rate can be calculated as:

$$
E^{\prime}=\frac{d E}{d T}=V_{m s}
$$

and the mean square voltage is calculated as

$$
V_{m s}=\frac{1}{\Delta T} \int_{0}^{\Delta T} V^{2}(t) d t
$$

where $V(t)$ is voltage of AE signals; $\Delta T$ is mean time interval. Energy release rate is expressed by the mean square voltage, as shown in Eq. (6.8).

Thus, the damage stability of rock can be judged by analyzing the energy release rate. Meanwhile, there is a positive correlation between mean square voltage and energy release rate. Therefore, the evolution process can be directly described by the variation of voltage to provide information or predicting of rock failure (Wang et al. 2015a, b).

\subsection{Evolution Patterns of Spatial-Temporal-Energy on Rock Fracture Surface}

Macroscopic failure of rock materials is the result of initiation, propagation and coalescence of rock cracks with a rapid release of transient elastic wave (AE). Much work of rock mechanics behavior and damage evolution were studied, and several valuable experimental results were obtained (Vidya Sagar et al. 2013). However, it is not comprehensive to study the evolution of rock failure process only from the features and roughness of fracture surface, rock failure process is a change status by energy release. Therefore, some work about energy point of rock failure were studied and several valuable experimental results were obtained (Peng et al. 2015). Wasantha et al. (2014) investigated the pattern of energy release during deformation of dry sandstone and saturated sandstone with different bedding directions under uniaxial compression. Carpinteri et al. (2006) studied the energy and dissipation 
energy of $\mathrm{AE}$ in the loading process of three point bending test of concrete beams in detail. Meanwhile, as we know, fracture surface is the main carrier of deformation and failure process; there are few researches which consider the relationship between fracture surface and energy of AE. Therefore, in this chapter, failure process of rock was studied through analyzing the changing pattern of time, space and energy of $\mathrm{AE}$ event on the fracture surface.

In this chapter, the spatial-temporal-energy evolution model of AE events on the fracture surface was established during rock failure, and the characteristics of fracture surface and the energy evolution were obtained during failure process, it provided us with scientific evidence for predicting rockburst.

\subsubsection{Experimental Setup and Procedure}

In this chapter, limestone samples were taken from the roof of coal seam at $1212 \mathrm{~m}$ depth in Xiezhuang Mine in Shandong province. These samples were processed as standard cylindrical rock samples of $50 \mathrm{~mm}$ in diameter and $100 \mathrm{~mm}$ in length. The experiment was adopted the axial displacement loading method, and the loaded rate was controlled at $0.005 \mathrm{~mm} / \mathrm{s}$. The loading machine and $\mathrm{AE}$ motoring system was operated synchronously.

The preamplifiers of $\mathrm{AE}$ were set at $40 \mathrm{~dB}$ before the samples were loaded. However, reducing the influence of environment noise, the threshold value of PCI was set at $45 \mathrm{~dB}$, and sampling rate was set at $1 \mathrm{MHz}$. AE testing system with 6 sensors for realizing real-time 3-D positioning of limestone samples during the entire deformation and fracture process. To reduce the influence of end-effects, 6 AE sensors were fitted on the limestone specimen $20 \mathrm{~mm}$ away from top and bottom of sample. Petroleum jelly and the adhesive band were used to fix the sensors on specimen surface. After the experiment, the relevant parameters of each event were analyzed during the entire process by Geiger algorithm, such as the $\mathrm{AE}$ rate, $\mathrm{AE}$ energy, $\mathrm{AE}$ position, and $\mathrm{AE}$ frequencies.

\subsubsection{Relationship Between Spatial Distribution of AE Events and Rock Fracture}

To study the evolution of spatial-temporal-energy evolution in the course of limestone failure, a series of $\mathrm{AE}$ tests were carried out for limestone failure under uniaxial compression. Stress strain data and AE data were obtained. Geiger algorithm was used to analyze $\mathrm{AE}$ events during loading process, and obtain the parameters of each event (time, position, energy). The corresponding parameters of $\mathrm{AE}$ events during the loading process of $\mathrm{X} 3$ rock sample were illustrated in Table 6.1. 
Table 6.1 AE events parameters of limestone sample X3 during the loading period

\begin{tabular}{l|l|l|l|l|l}
\hline \multirow{2}{*}{$\begin{array}{l}\text { Events } \\
\text { ID }\end{array}$} & \multirow{2}{*}{ Time } & \multicolumn{3}{|l|}{ Position Coordinates } & \multirow{2}{*}{ Energy } \\
\cline { 3 - 5 } & & $\mathrm{X}$ & $\mathrm{Y}$ & $\mathrm{Z}$ & \\
\hline 1 & 0.27 & -3.21 & 8.23 & 5.19 & 16 \\
\hline 2 & 0.29 & -12.18 & 10.16 & 15.13 & 27 \\
\hline 3 & 0.50 & -1.56 & -3.27 & 36.80 & 37 \\
\hline 4 & 0.73 & -9.22 & -11.06 & 36.79 & 19 \\
\hline 5 & 0.74 & 3.46 & -18.6 & 41.23 & 30 \\
\hline 6 & 0.84 & -7.58 & 8.48 & 21.17 & 51 \\
\hline 7 & 1.27 & 0.93 & -19.27 & 40.59 & 1 \\
\hline$\ldots$ & $\ldots$ & $\ldots$ & $\ldots$ & $\ldots$ & $\ldots$ \\
\hline$\ldots$ & $\ldots$ & $\ldots$ & $\ldots$ & $\ldots$ & $\ldots$ \\
\hline$\ldots$ & $\ldots$ & $\ldots$ & $\ldots$ & $\ldots$ & $\ldots$ \\
\hline 934 & 3.22 & -3.34 & -4.48 & 36.78 & 6 \\
\hline 935 & 3.68 & -13.06 & -9.25 & 36.73 & 2 \\
\hline 936 & 3.76 & -10.22 & -12.13 & 38.79 & 3 \\
\hline
\end{tabular}

A large number of $\mathrm{AE}$ events were obtained immediately, due to the internal deformation and cracks propagation. AE events reached several thousand or even tens of thousands during a loading process, if all the events were analyzed, then the workload was too great. Many small energy events could be ignored in the rock failure process. As a dominant reason for the ultimate failure of rock, which could only be large energy events. So, a large number of AE events were screened for energy, and finally the appropriate threshold of energy was determined. AE events over threshold were defined as a strong $\mathrm{AE}$ event. Comparison of $\mathrm{AE}$ spatial distribution and actual rupture propagation before and after the screening of X3 rock sample was demonstrated in Fig. 6.13.

Comparison of $\mathrm{AE}$ events spatial distribution and actual fracture propagation before and after the screening of X3 rock sample was shown in Fig. 6.13. As shown in Fig. 6.13b, AE events could be better reflected the evolution characteristics of internal rupture. There were many AE events in Fig. 6.13a, which leaded to the chaotic distribution of $\mathrm{AE}$ events in rock sample, and it was difficult to determine the specific location of main fracture surface. As shown in Fig. 6.13b, compared with the actual fracture propagation, $\mathrm{AE}$ events were mainly distributed near the main fracture surface of rock sample, which could clearly reflect the initiation, propagation and coalescence process of main fracture surface. Therefore, it is reasonable to study the spatial-temporal-energy evolution characteristics of $\mathrm{AE}$ in the loading process using energy screening method. 


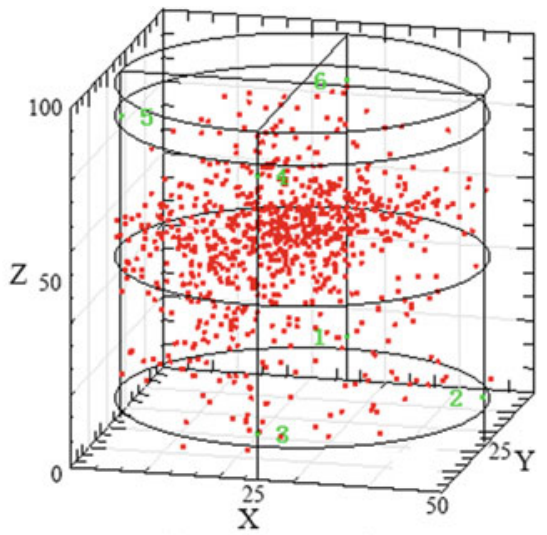

(a) Before screening

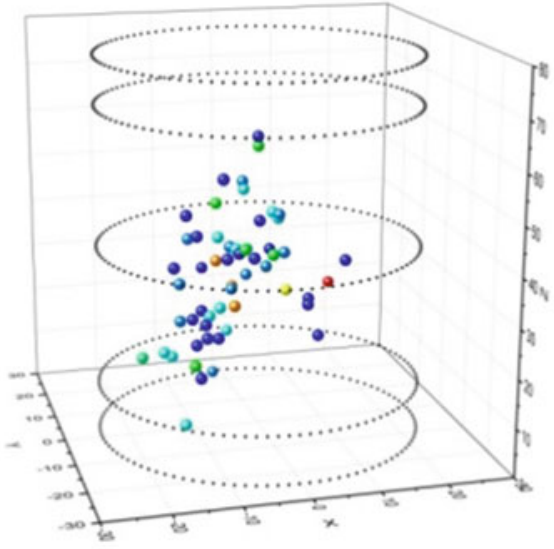

(c) AE events characterized by energy

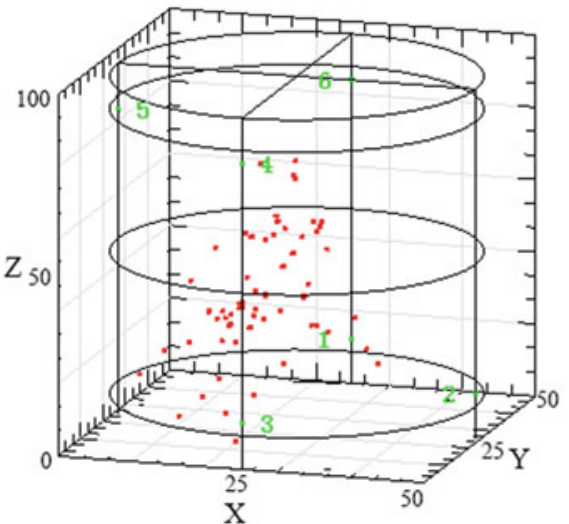

(b) After screening

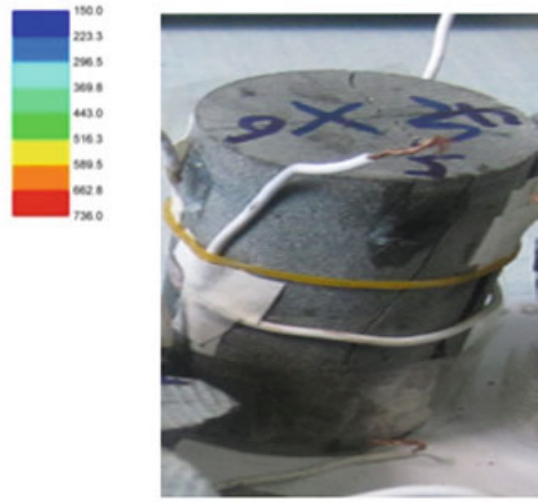

(d) actual rupture propagation

Fig. 6.13 Comparison of AE spatial distribution and actual rupture propagation

\subsubsection{Spatial-Temporal Evolution of Strong AE Events on Rock Fracture}

It was found that $\mathrm{AE}$ spatial distribution contained full information about internal deformation characters and cracks evolution of rock failure. Therefore, it provided a basis for studying the propagation process and spatial morphology of rock during loading process. AE localization of sample X3 in different loading period under uniaxial compression was shown in Figs. 6.14 and 6.15, where the color represented the magnitude of events energy value.

Analyzing the spatial-temporal-energy evolution characteristics of strong AE events, the spatial-temporal-energy evolution model of rock fracture surface was established. In this chapter, using the energy screening methods, it was showed that 


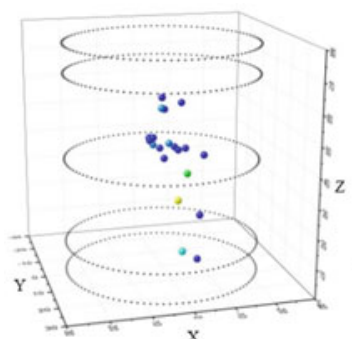

(a) $20 \% \sigma c$

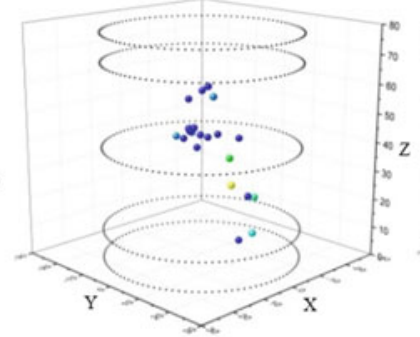

(b) $40 \% \sigma \mathrm{c}$

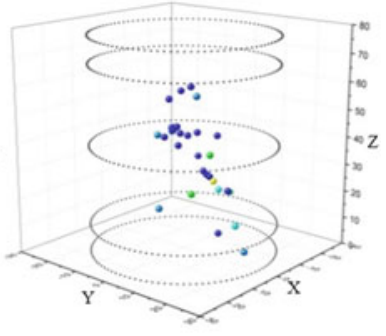

(c) $60 \% \sigma \mathrm{c}$

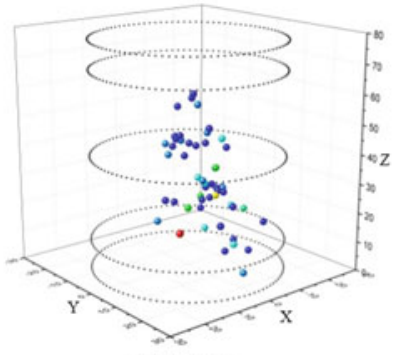

(d) $80 \%$ бc

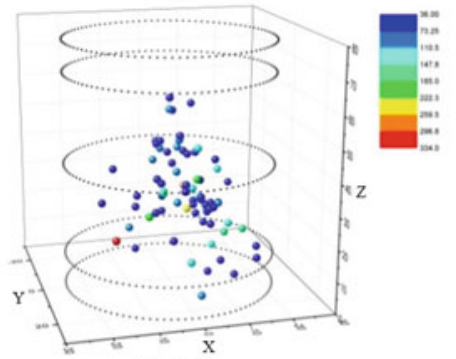

(e) $100 \% \sigma_{c}$

Fig. 6.14 AE localization of sample $X 3$ in different loading period

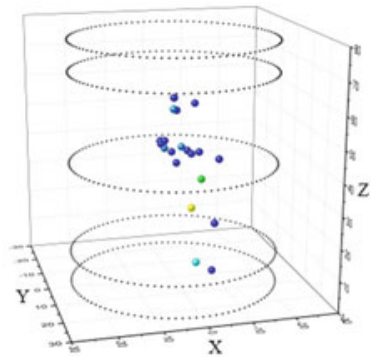

(a) $0 \sim 20 \%$ бc

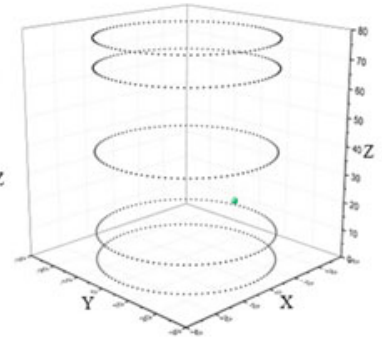

(b) $20 \% \sim 40 \%$ бc

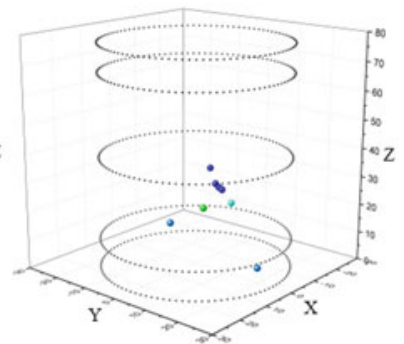

(c) $40 \% \sim 60 \% \sigma \mathrm{c}$

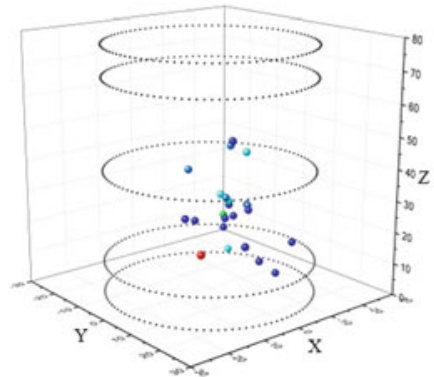

(d) $60 \% \sim 80 \% \sigma \mathrm{c}$

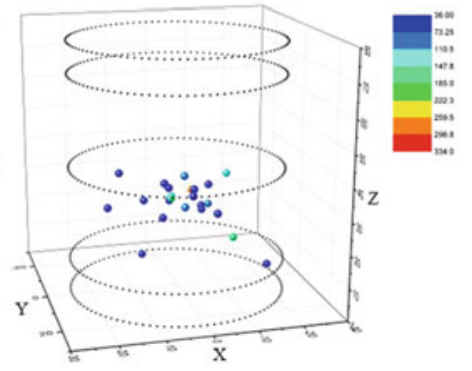

(e) $80 \% \sim 100 \%$ бc

Fig. 6.15 AE localization of sample $\mathrm{X} 3$ in different loading period (piecewise representation) 
most of strong AE events were distributed on rock fracture surface. As a matter of fact, the weak AE events had little effect on rock failure, and the occurrence of strong AE events corresponded to damage deformation. Therefore, it could be better analyzed the spatial position, propagation direction and spatial shape of cracks propagation in rock samples, and it could be more accurately determine the location of fracture surface, so as to provide predictions for the final rupture of rock condition.

\subsubsection{Spatial-Temporal-Energy Evolution Model of Strong $A E$ Events in Limestone Fracture}

As shown in Fig. 6. 16, it was the relationship curves between cumulative energy of strong AE events and time in the fracture surface of rock samples during the loading process. Take X3 rock sample for example, when stress was less than $20 \%$ of the peak stress, in the fracture compaction stage, more low energy events were monitored in the lower part of rock sample, and the middle energy events were relatively large in the lower part, which may be the internal joint fracture. The lower part was more developed, under the action of external load joints began to close, resulting in AE events, and activities were more intense. With the stress increased, rock sample entered the cracks initiation stage, and a small amount of low energy AE events were observed at the top and bottom of rock sample. The fracture surface did not form at this stage. When stress reached at 40-60\% of the peak stress, rock specimen entered cracks in the stable development stage, and $\mathrm{AE}$ events were significantly increased in the lower part of rock sample, event energy was larger, forming the strip shape with the pre-generated event. When stress reached at $80 \%$ of the peak stress, rock sample entered the unstable development stage of cracks, AE events increased rapidly and energy increased significantly. AE events on the strip began to be concentrated, and then internal cracks began to pass through, forming macro-cracks, and fracture surface was formed. In the later of this stage, number of $\mathrm{AE}$ events and the accumulated energy hardly increased, and there was a brief silence zone, namely, AE "quiet period", which could be used as a predicting point of rock destabilization failure (Wang 2015b). When stress exceeded the peak stress and entered the failure stage, AE event was obviously reduced compared to the previous stage. The macro fracture connection and coalescence of rock sample form the main fracture surface, and the rock sample was failure.

From the above analysis, it could be seen found that the formation of fracture surface mainly concentrated on the plastic stage and the failure stage. Therefore, the pattern of energy evolution pattern of rock fracture surface should begin with the plastic stage, which could be better revealed the evolution pattern of propagation and coalescence of internal cracks in rock samples.

The cumulative energy of plastic section of each rock sample, the abscissa was as the time, and the ordinate was selected as the cumulative energy. The Gauss 

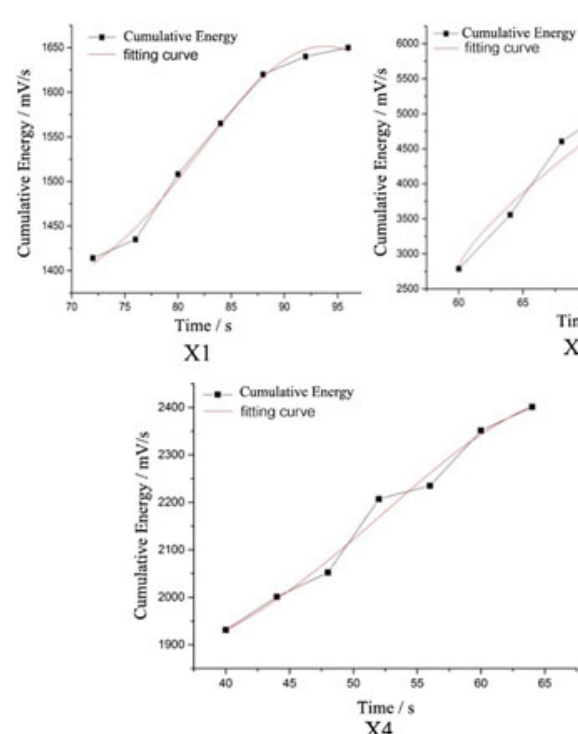
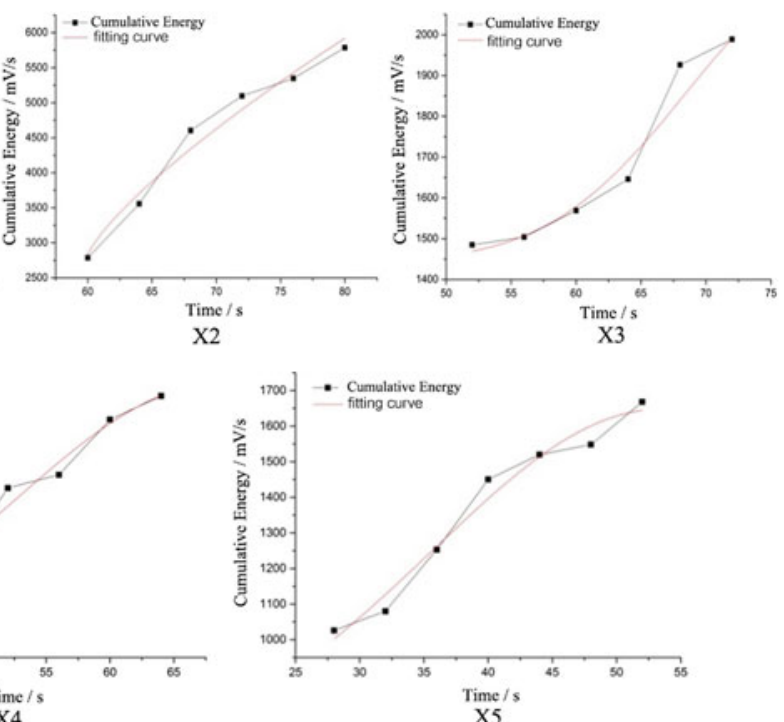

Fig. 6.16 Relationship curves between cumulative energy of strong AE events and time in the fracture surface

Amp function was used to fit, and the fitting function was $y=y_{0}+A e^{-\frac{\left(x-x_{c}\right)^{2}}{2 \omega^{2}}}$, the dependent variable $y$ was used to represent the cumulative AE energy, $x_{c}$ was used to represent the critical moment, $y_{0}$ was used to represent cumulative AE energy in the plastic stage, A was used to represent the amplitude of cumulative AE energy, $\omega$ was the relevant parameters, and it could be satisfied the equation $2 \omega=F W H M / \operatorname{sqrt}(\ln (4))$, which could calculate the value of $\omega$. So the original formula changes to $E=E_{0}+A \mathrm{e}^{-\frac{\left(t-t_{c}\right)^{2}}{2 \omega^{2}}}$. The obtained AE data were analyzed in the experiment, and the cumulative energy-time curve of strong event in fracture surface was plotted. Then the above functions were used to fit, the fitting results were shown in Fig. 6.16, and the related parameters were shown in Table 6.2.

Table 6.2 Related parameters and equations of fitting curves

\begin{tabular}{l|l|l|l|l|l}
\hline \multirow{2}{*}{ Specimen ID } & \multicolumn{4}{l}{ Related parameters } & \multirow{2}{l}{ Fitting equations } \\
\cline { 2 - 6 } & $\mathrm{E}_{0}$ & $\mathrm{~A}$ & $\mathrm{t}_{\mathrm{c}}$ & $\omega$ & \\
\hline $\mathrm{X} 1$ & 1357 & 293 & 93.8 & 11.6 & $E=1357+293 \mathrm{e}^{\frac{(t-9.3 .8)^{2}}{2 \times 11.6)^{2}}}$ \\
\hline $\mathrm{X} 2$ & 1415 & 4223 & 78.3 & 15.8 & $E=1415+4223 \mathrm{e}^{\frac{(t-78.3)^{2}}{2 \times 15.8^{2}}}$ \\
\hline $\mathrm{X} 3$ & 1443 & 684 & 79.1 & 10.6 & $E=1443+684 \mathrm{e}^{-\frac{(t-79.1)^{2}}{2 \times 10.6^{2}}}$ \\
\hline $\mathrm{X} 4$ & 1797 & 630 & 79.5 & 16.2 & $E=1443+684 \mathrm{e}^{\frac{(t-79.1)^{2}}{2 \times 10.62^{2}}}$ \\
\hline $\mathrm{X} 5$ & 833 & 806 & 53.5 & 17.9 & $E=833+806 \mathrm{e}^{-\frac{(t-53.5)^{2}}{2 \times 17.9)^{2}}}$ \\
\hline
\end{tabular}




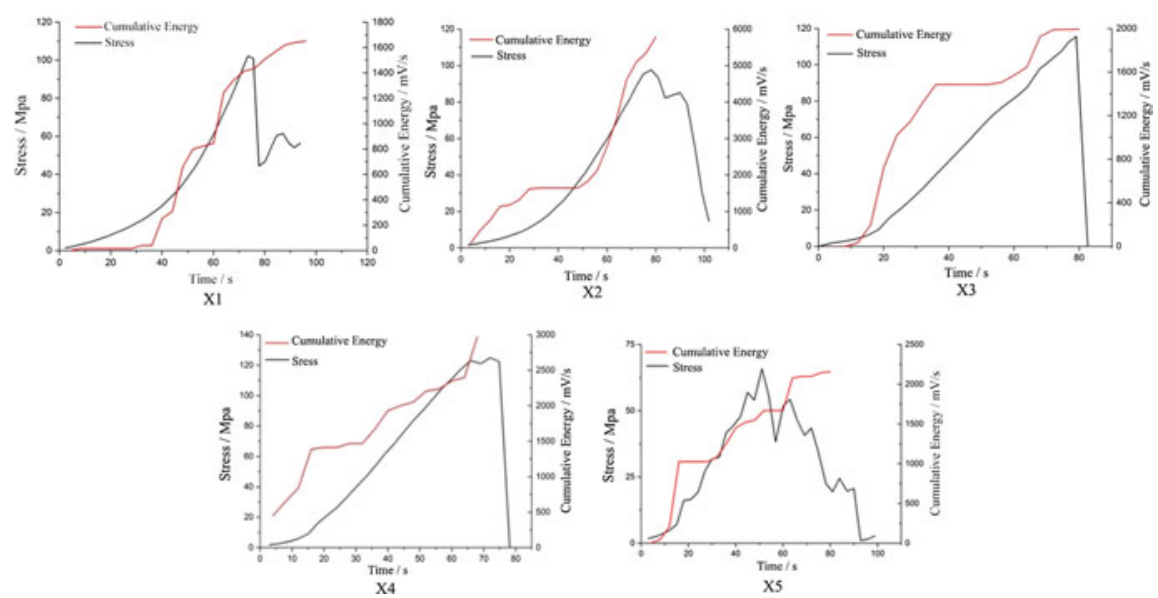

Fig. 6.17 Relationship fitting curves between cumulative energy of strong AE events and time in the fracture surface

As shown in Fig. 6.17, besides the rock samples X3 and X5 (the correlation coefficient of X3 is 0.93 and X5 is 0.91 ), the fitting correlation coefficients of other 3 rock samples were all above 0.97. The results showed that Gauss Amp function fitted well, and the parameters $E_{0}, A, t_{c}$ and $\omega$ could be obtained by fitting the results.

During the loading process, the input energy was mainly converted into two parts: one part was dissipated in the form of damage energy and plastic deformation energy of rock specimen. The other part was accumulated inside the rock sample in the form of elastic strain energy and could be released during unloading. The ratio of elastic energy and dissipated energy to input energy had a great influence on rock deformation and failure modes. As a part of dissipation energy, AE energy might be related to the external input energy. The area between stress-strain curve and transverse axis was the strain energy density. The related parameters of samples energy were shown in Table 6.3.

As shown in Table 6.3, vary of strain energy density and cumulative AE energy was showed at the plastic stage. However, when strain energy density was large,

Table 6.3 Related parameters of samples energy

\begin{tabular}{l|l|l|l}
\hline $\begin{array}{l}\text { Specimen } \\
\text { ID }\end{array}$ & $\begin{array}{l}\text { Strain energy } \\
\text { density }\end{array}$ & $\begin{array}{l}\text { Cumulative AE energy at the plastic } \\
\text { stage }\end{array}$ & $\begin{array}{l}\text { Proportion } \\
(\%)\end{array}$ \\
\hline $\mathrm{X} 1$ & 0.266419 & 1357 & 0.51 \\
\hline $\mathrm{X} 2$ & 0.214304 & 1415 & 0.66 \\
\hline $\mathrm{X} 3$ & 0.273068 & 1443 & 0.53 \\
\hline $\mathrm{X} 4$ & 0.354202 & 1797 & 0.51 \\
\hline $\mathrm{X} 5$ & 0.118236 & 833 & 0.70 \\
\hline
\end{tabular}


cumulative AE energy corresponding was correspondingly large. Its proportion in a certain range ranged from 0.5 to $0.7 \%$.

In conclusion, it could be concluded that cumulative AE energy increased with time during the failure process. Especially, after the plastic stage, cumulative AE energy of strong events in the fracture surface conformed to Gauss Amp function distribution. Therefore, the spatial-temporal-energy evolution model of limestone on the fracture surface was proposed:

$$
E=k \int_{0}^{\varepsilon_{c}} \sigma d \varepsilon+A \mathrm{e}^{-\frac{\left(t-t_{c}\right)^{2}}{2 \omega^{2}}}
$$

where $k$ is a material constant, and its value is between 0.5 and $0.7 \% ; t_{c}$ is the critical moment; $t$ is the loading time, and it ranges from the initial stage of plastic stage to the peak stress; $\varepsilon_{c}$ is strain corresponding to peak stress; $\omega$ is the coefficient in Gauss Amp function; $A$ is the increment of cumulative AE energy from the beginning of plastic phase to the peak stress; $E$ is cumulative AE energy of strong events.

Energy of AE events directly characterized the intensity of internal mesoscopic damage, and the weak event had little effect on rock failure, and the ultimate failure of rock was dominated by strong event. On the basis of predecessors, energy was taken into account in the spatial-temporal evolution analysis of AE events, so as to analyze the spatial-temporal-energy evolution of AE events on the fracture surface. The proposed spatial-temporal-energy evolution model combined the spatial-temporal events and energy of fracture surface in the process of limestone rupture and failure, and it described the energy evolution pattern in the formation of fracture surface under the uniaxial compression. The model was used to describe the energy change process of fracture surface systematically, and it provided a theoretical basis for predicting rockburst. However, this model is only applicable to the uniaxial compression test of limestone, and further study is needed for other rock and other stress conditions.

\subsubsection{Spatial Fractal Dimension Evolution Model of AE Events on Fracture}

In 1973, mathematician Mandelbrot first proposed the idea of using fractional and fractal geometry to describe irregular objects and chaotic phenomena in nature (Mandelbrot 1983). Analyzing AE signal produced in the propagation of micro-cracks, it was found that AE parameters followed not only fractal characteristics in time, but also fractal characteristic in spatial distribution. The balls covering method or the circle covering method after projection were widely used for three-dimensional distribution of AE events. For the cylindrical rock specimens, 
column covering method was more appropriate. In this method, the spatial distribution characteristics of AE events were apt to be described exactly. Due to the shape of rock specimens, it was very convenient for the method to calculate the fractal dimension of spatial $\mathrm{AE}$ event distribution according to the coordinates of AE events. Therefore, the method could be used to determine the critical value of rock failure, predict the rockbursts, and evaluate the stability of rockmass.

When AE events were covered by a cylinder with radius $r$ and height $h$, the relationship between $\mathrm{AE}$ event number and the radius of cylinder was:

$$
M_{(r)} \propto r^{2} h \propto C_{1} r^{3}
$$

where $C 1$ represents height-radius ratio. Equation (6.10) could be further expressed as:

$$
\log M_{(r)}=\log C+\log C_{1}+D \log r
$$

where $r$ is a given radius, $M(\mathrm{r})$ is a value which can be obtained through Eq. (6.11). In a double logarithmic coordinate system, point series (log $r, \log \mathrm{M}(\mathrm{r})$ ) corresponding to given radii can be portrayed. The spatial AE event distribution has fractal characteristic in the range of a given scale if those points approximately distribute along a straight line. The slope of line is the exact fractal dimension of spatial AE event distribution.

Based on the above-mentioned column covering method, using the different radius $r$ of the cylinder to cover the strong AE events, the relationship between number of strong events $\mathrm{M}(\mathrm{r})$ and radius was obtained. In a double logarithmic coordinate system, point series $(\log r, \log \mathrm{M}(\mathrm{r}))$ corresponding to given radii could be portrayed. Then the linear point of data points was fitted, and the obtained slope was the fractal dimension of spatial distribution of large events in rock sample under the stress level. The curve between the spatial fractal dimension and the stress level of strong AE events of limestone rock samples was shown in Fig. 6.18.

Fig. 6.18 Relationship curves between spatial fractal value of $\mathrm{AE}$ events dimensional distribution and stress

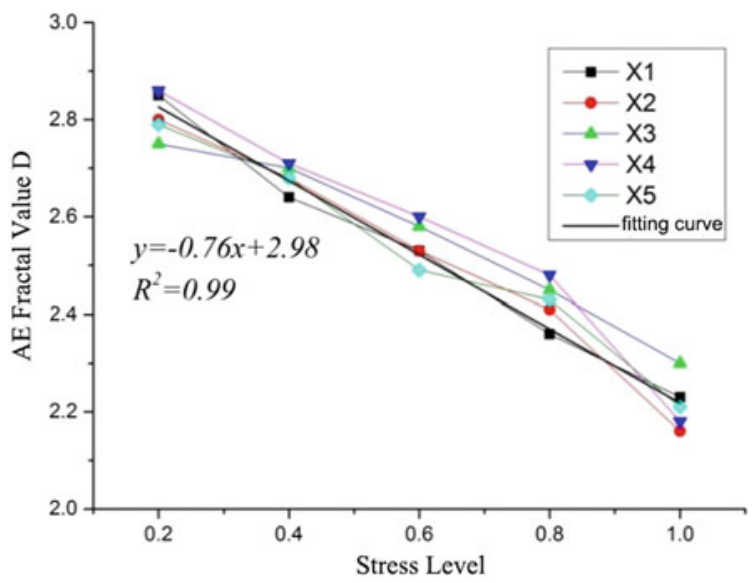


When stress was at a low level (below $0.2 \sigma_{\mathrm{c}}$ ), the spatial fractal dimension, close to 3, was relatively large indicated that $\mathrm{AE}$ events in this stage were more evenly distributed in the interior space of rock samples. With the increase of stress, rock sample entered the cracks initiation stage and cracks stabilization expansion stage $\left(0.2-0.7 \sigma_{\mathrm{c}}\right)$. Because of less AE events, $D$ value of this stage decreased slowly. With the increase of stress, rock specimen entered the unsteady expansion stage $\left(0.7-0.9 \sigma_{\mathrm{c}}\right)$, the internal damage increased and the fractal dimension decreased continuously. When stress value reached about $80 \%$ of the peak stress, $D$ value decreased rapidly, indicated that the internal events began to accumulate near the macroscopic main fracture surface. When stress reached the peak stress, the macro-fracture surface was formed gradually, and $D$ value dropped to the minimum value, which was close to 2.2 .

By analyzing the relationship curve between the spatial fractal dimension and the stress level of AE event, the spatial fractal dimension decreased linearly with the increase of stress level. Therefore, the least squares method was used to fit the curve, and the fitted curve was shown in Fig. 6.18. The fitted equation was as follow:

$$
D=-0.76 \frac{\sigma}{\sigma_{c}}+2.98
$$

where $D$ is the spatial fractal dimension, and its value is between 2 and $3 ; \sigma_{c}$ is the peak stress; $\sigma$ is the stress value during loading process.

\subsection{Conclusion}

Rock failure was accompanied by changing of AE parameters as well. In view of this issue, this section was built on the laboratory test, explored and quantized the feature of failure precursory information, and obtained the following conclusions:

(1) Though the distribution was very heterogeneous, through analyzed the feature of spatio-temporal evolution in the different loading stage, we still found two main phenomenons after summarizing all sample results: intensive phenomenon and zonation.

(2) The characteristic point of the relatively quiet period was defined as a characteristic precursor point of rock failure. The ratio of stress at the relatively quiet period was from 88 to $98 \%$ of the peak stress in the unstable propagation stage.

(3) In the plastic stage, AE energy rapidly increased and remained at high values indicating intense energy release before rock failure. In the failure stage, AE energy sharply decreased and rock instability occurred. The corresponding time, when AE energy release rate reached at the maximum, can be suggested as the critical point for predicting rock failure. Meanwhile, AE energy release rate could be considered as an important rock failure index, which might provide physical basis for predicting rockburst. 
(4) Strong AE events could fully reflect the evolution of internal damage and deformation, and were concentrated in the vicinity of main fracture surface. Through the spatial distribution analysis of strong AE events, the position of rupture surface could be determined more accurately.

(5) The range of fractal dimension of strong AE event was from 2 to 3 , the value of the initial stage was close to 3 , and the value of final failure stage was close to 2 . The spatial fractal dimension showed a sharp decrease near the yield point (about $0.8 \sigma_{\mathrm{c}}$ ), indicating that rock was about to lose stability and could be used as a precursory feature of rockburst. Moreover, there was a linear relationship between fractal dimension and stress level.

(6) The fracture surface was mainly produced in the plastic stage and the failure stage under uniaxial compression. Cumulative AE energy of fracture surface conformed to Gauss Amp function distribution. Therefore, the spatial-temporal-energy evolution model in the fracture surface for strong AE event was established.

\section{References}

Carpinteri A, Lacidogna G (2006) Monitoring the durability performances of concrete and masonry structures by acoustic emission technique. In: Fracture of nano and engineering materials and structures, pp 781-782

Carpinteri A, Lacidogna G, Paggi M (2007) Acoustic emission monitoring and numerical modeling of FRP delamination in RC beams with non-rectangular cross-section. Mater Struct 40:553-566

Mandelbrot BB (1983) The fractal geometry of nature. New York: WH freeman

Lacidogna G, Carpinteri A, Manuello A, Durin G, Schiavi A, Niccolini G, Agosto A (2011) Acoustic and electromagnetic emissions as precursor phenomena in failure processes. Strain 47:144-152

Mandelbrot BB (1983) The fractal geometry of nature. New York: WH freeman

Meng Q, Zhang M, Han L, Pu H, Nie T (2016) Effects of acoustic emission and energy evolution of rock specimens under the uniaxial cyclic load/unload compression. Rock Mech Rock Eng 49:3873-3886

Miller, RK, Pollock, AA, Finkel P, Watts DJ, Carlyle JM, Tafuri AN, Yezzi, JJ (1999) The development of acoustic emission for leak detection and location in liquid-filled, buried pipelines. In: Acoustic emission: standards and technology update. ASTM International

Peng R, Ju Y, Wang JG, Xie H, Gao F, Mao L (2015) Energy dissipation and release during coal failure under conventional triaxial compression. Rock Mech Rock Eng 48:509-526

Vidya Sagar R, Prasad RV, Raghu Prasad BK, Rao MVMS (2013) Microcracking and fracture process in cement mortar and concrete: a comparative study using acoustic emission technique. Exp Mech 53:1161-1175

Wang C (2014) Identification of early-warning key point for rockmass instability using acoustic emission/micro seismic activity monitoring. Int J Rock Mech Min 71:171-175

Wang C, Bao T, Lu H, Liu L, Lu Z, Li W, Yu Q (2015a) Variation regulation of the acoustic emission energy parameter during the failure process of granite under uniaxial compression. Mater Test 57(9):755-760

Wang CL, Lu H, Wang FL et al (2015b) Characteristic point of the relatively quiet period for limestone failure under uniaxial compression. J Test Eval 43(6):1296-1307

Wasantha PLP, Ranjith PG, Shao SS (2014) Energy monitoring and analysis during deformation of bedded-sandstone: use of acoustic emission. Ultrasonics 54:217-226 
Open Access This chapter is licensed under the terms of the Creative Commons Attribution-NonCommercial 4.0 International License (http://creativecommons.org/licenses/by-nc/ 4.0/), which permits any noncommercial use, sharing, adaptation, distribution and reproduction in any medium or format, as long as you give appropriate credit to the original author(s) and the source, provide a link to the Creative Commons license and indicate if changes were made.

The images or other third party material in this book are included in the book's Creative Commons license, unless indicated otherwise in a credit line to the material. If material is not included in the book's Creative Commons license and your intended use is not permitted by statutory regulation or exceeds the permitted use, you will need to obtain permission directly from the copyright holder.

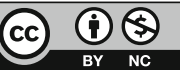

